\title{
A Study on Menstruation and Personal Hygiene among Adolescent Girls
}

\author{
Deepa Amgoth* and R. Geetha Reddy \\ Department of Home Science Extension and Communication Management, Hyderabad, \\ Professor Jayashankar Telangana State Agricultural University, Telangana, India
}

*Corresponding author

\section{A B S T R A C T}

\begin{tabular}{|c|}
\hline Keywords \\
\hline $\begin{array}{l}\text { Adolescence, } \\
\text { Menstruation, } \\
\text { Menarche, periods, } \\
\text { Taboos, Ex post } \\
\text { facto, Hygiene } \\
\text { practices, Pads }\end{array}$ \\
\hline Article Info \\
\hline $\begin{array}{l}\text { Accepted: } \\
\text { 04 January } 2018 \\
\text { Available Online: } \\
10 \text { February } 2019\end{array}$ \\
\hline
\end{tabular}

\section{Keywords}

\section{Introduction}

Adolescence is regarded, as a unique phase of human development. It is a transitional phase of growth and development between childhood and adulthood. In India, limited access to products of sanitary hygiene and lack of safe sanitary facilities could increase the likelihood of resorting to unhygienic practices to manage menstruation.

All myths and taboos such as not taking bath, avoiding hot and cold foods, avoiding exercise, have no scientific support, and need to be eliminated to release menstruation

\begin{abstract}
Adolescence is a transition period from childhood to adult life during which pubertal development and sexual maturation take place, thus making physiological development a challenge adolescents have to face. There is a substantial lacuna in the knowledge towards menstruation among adolescent girls; hence, an attempt was made to study on Menstruation and Personal hygiene among Adolescent girls. Ex post facto research design Tes uned for the study. The locale of the study was Midjil of Mahabubnagar district in years were purposively selected. Structured questionnaire was used to examine the existing knowledge and hygiene practices regarding menstruation. Frequencies and percentages were used to analyse the collected data. Results revealed that prior information about menarche before its attainment was not available to $53 \%$ of the adolescent girls in the present study. About $30 \%$ of the respondents use sanitary pads during their periods. Majority (77\%) of the adolescent girls did not change their pads or cloths more than two times during menstruation and, hence indicated low hygiene practice during menstruation.
\end{abstract}

anxiety among girls. An adolescent girl should be made aware of the phenomenon of menstruation before menarche, so as to enable her to accept it as a normal developmental process and manage it appropriately.

Menstrual hygiene and management can be essential in ensuring that your everyday life is not interrupted by menstruation. It ensures that you can continue with your daily routine such as going to school, going to work or doing household chores. In this sense, maintaining proper menstrual hygiene is important for your wellbeing and development. 
Hema et al., (2017) studied about menstrual hygiene and related personal hygiene practices among adolescent girls in rural Puducherry. A community based descriptive cross sectional study was conducted by using semi-structured questionnaire on 528 adolescent girls by complete enumeration. The results were Majority $(89.2 \%)$ of the adolescent girls was using sanitary pads. $65.3 \%$ girls changed their soaked absorbent 2-5 times in a day and unhygienic practices were noticed.

Vyas et al., (2017) investigated a study of nutritional status and personal hygiene among adolescent girls of rural Bikaner. The size of this study was 489 and the research design was community based cross-sectional study. The results of this study were anaemia was common problem among adolescent girls in rural area. The personal hygiene was good among adolescent girls.

Kartik et al., (2016) investigated about knowledge and practices regarding menstrual hygiene among urban adolescent girls in Bangalore, India. An epidemiologic study was undertaken using cross-sectional study method among 550 school- going adolescent girls aged 13-16 years. Data was collected using a pre-tested questionnaire. Overall, 69\% of adolescent girls were using sanitary napkins as menstrual absorbent. There is a need to equip the adolescent girls with knowledge regarding safe, hygienic practices to enable them to lead a healthy reproductive life.

Van Eijk et al., (2016) investigated on menstrual hygiene management among adolescent girls in India: a systematic review and meta-analysis. The population of this study was 138 adolescent girls; the conclusion of this study was Strengthening of MHM programmes in India are needed. Education on awareness, access to hygienic absorbents and disposal of MHM items need to be addressed.
To study the Profile characteristics of rural adolescent girls.

To study the existing knowledge about menstruation among adolescent girls.

To study the menstrual health practices among adolescent girls.

\section{Materials and Methods}

Based upon the nature of the research problem and objectives of the present study, Ex post facto research design was opted for the study. The locale of the study was Midjil of Mahabubnagar district in Telangana State.

The samples were selected was purposely selected for the present study. Nearby Government school was purposively selected because of the availability and easy accessibility of the respondents. In this study, samples comprising of 30 adolescent girls were selected for the study, under the age group of 12-16 years.

Structured questionnaire schedule was designed by the investigator for the study which includes general profile of the adolescents about menstruation. The questionnaire has two areas which consist of existing knowledge and health practices about menstruation. Frequencies and percentages were used to analyse the collected data.

\section{Results and Discussion}

\section{General profile of the respondents}

Majority $57 \%$ of the adolescent girls are of age 14 years. The nuclear families of the respondents are of $87 \%$. About $93 \%$ of the respondents comprise of low income. The caste BC and ST categories are of $47 \%$ each of the respondents (Table 1). 
Table.1 General profile of the respondents

\begin{tabular}{|c|c|c|c|}
\hline \multirow[t]{2}{*}{ S.No. } & \multirow[t]{2}{*}{ Variables } & \multicolumn{2}{|c|}{ Respondents $(\mathrm{N}=\mathbf{3 0})$} \\
\hline & & $\mathbf{N}$ & $\%$ \\
\hline \multirow[t]{4}{*}{1.} & \multicolumn{3}{|l|}{ Age } \\
\hline & 12-13 years & 6 & 20 \\
\hline & 14 years & 17 & 57 \\
\hline & $15-16$ years & 7 & 23 \\
\hline \multirow[t]{3}{*}{2.} & \multicolumn{3}{|l|}{ Type of family } \\
\hline & Nuclear & 26 & 87 \\
\hline & Joint & 4 & 13 \\
\hline \multirow[t]{4}{*}{3.} & Income levels & & \\
\hline & Low(Below 60,000) & 28 & 93 \\
\hline & $\operatorname{Medium}(60,000-1,00,000)$ & 1 & 3 \\
\hline & High(Above $1,00,000)$ & 1 & 4 \\
\hline \multirow[t]{4}{*}{4.} & \multicolumn{3}{|l|}{ Caste } \\
\hline & $\mathrm{BC}$ & 14 & 47 \\
\hline & $\mathrm{SC}$ & 2 & 6 \\
\hline & ST & 14 & 47 \\
\hline
\end{tabular}

Table.2 Existing knowledge about menstruation among adolescent girls

\begin{tabular}{|c|c|c|c|}
\hline \multirow[t]{2}{*}{ S.No. } & \multirow[t]{2}{*}{ Variables } & \multicolumn{2}{|c|}{ Respondents $(\mathrm{N}=\mathbf{3 0})$} \\
\hline & & $\mathbf{N}$ & $\%$ \\
\hline \multirow[t]{6}{*}{1.} & \multicolumn{3}{|c|}{ Knowledge of organ from where bleeding occurs } \\
\hline & Uterus & 13 & 43 \\
\hline & Kidney & 2 & 7 \\
\hline & Bladder & 0 & 0 \\
\hline & Stomach & 0 & 0 \\
\hline & Do not know & 15 & 50 \\
\hline \multirow[t]{3}{*}{2.} & \multicolumn{3}{|c|}{ Menstrual blood contains dangerous substances } \\
\hline & Yes & 12 & 40 \\
\hline & No & 18 & 60 \\
\hline \multirow[t]{3}{*}{3.} & \multicolumn{3}{|c|}{ Pregnant women menstruate } \\
\hline & Yes & 12 & 40 \\
\hline & No & 18 & 60 \\
\hline \multirow[t]{3}{*}{4.} & \multicolumn{3}{|c|}{ Received any information prior menarche } \\
\hline & Yes & 14 & 47 \\
\hline & No & 16 & 53 \\
\hline \multirow[t]{5}{*}{5.} & \multicolumn{3}{|c|}{ Source of information (before menarche) } \\
\hline & Mother & 22 & 73 \\
\hline & Sister & 3 & 10 \\
\hline & Friends and relatives & 4 & 13 \\
\hline & Teachers & 1 & 4 \\
\hline
\end{tabular}


Table.3 Menstrual health practices among adolescent girls

\begin{tabular}{|c|c|c|c|}
\hline \multirow[t]{2}{*}{ S. No. } & \multirow[t]{2}{*}{ Variables } & \multicolumn{2}{|c|}{ Respondents $(\mathrm{N}=30)$} \\
\hline & & $\mathbf{N}$ & $\%$ \\
\hline \multirow[t]{4}{*}{1.} & \multicolumn{3}{|l|}{ Age at menarche } \\
\hline & $<12$ years & 12 & 40 \\
\hline & $12-14$ years & 16 & 53 \\
\hline & $>14$ years & 2 & 7 \\
\hline \multirow[t]{3}{*}{2.} & \multicolumn{3}{|l|}{ Menstrual cycle } \\
\hline & Regular & 25 & 83 \\
\hline & Irregular & 5 & 17 \\
\hline \multirow[t]{4}{*}{3.} & \multicolumn{3}{|c|}{ Duration of menstrual flow in days } \\
\hline & $<2$ & 4 & 13 \\
\hline & $2-7$ & 24 & 80 \\
\hline & $>7$ & 2 & 7 \\
\hline \multirow[t]{4}{*}{4.} & \multicolumn{3}{|c|}{ Amount of menstruation } \\
\hline & Scanty & 4 & 13 \\
\hline & Normal & 22 & 74 \\
\hline & Excess & 4 & 13 \\
\hline \multirow[t]{3}{*}{5.} & \multicolumn{3}{|l|}{ Passage of clots } \\
\hline & Yes & 4 & 13 \\
\hline & No & 26 & 87 \\
\hline \multirow[t]{4}{*}{6.} & \multicolumn{3}{|c|}{ Experience at Menarche } \\
\hline & Confusing & 9 & 30 \\
\hline & Expectant & 14 & 47 \\
\hline & Frightened & 7 & 23 \\
\hline \multirow[t]{4}{*}{7.} & \multicolumn{3}{|c|}{ Type of absorbent used during menstruation } \\
\hline & Pads & 21 & 70 \\
\hline & Fresh cloth & 9 & 30 \\
\hline & Reusable cloth & - & - \\
\hline \multirow[t]{4}{*}{8.} & \multicolumn{3}{|c|}{ Number of times absorbent changed (per day) } \\
\hline & $<2$ times & 23 & 77 \\
\hline & $2-5$ times & 6 & 20 \\
\hline & $>5$ times & 1 & 3 \\
\hline \multirow[t]{3}{*}{9.} & \multicolumn{3}{|l|}{ Daily bath } \\
\hline & Yes & 28 & 93 \\
\hline & No & 2 & 7 \\
\hline \multirow[t]{5}{*}{10.} & \multicolumn{3}{|c|}{ Disposal of used menstrual absorbent } \\
\hline & Dust bin & 7 & 23 \\
\hline & Wash and reuse & - & - \\
\hline & Burn/ bury & 18 & 60 \\
\hline & Flush in toilet & 5 & 17 \\
\hline
\end{tabular}




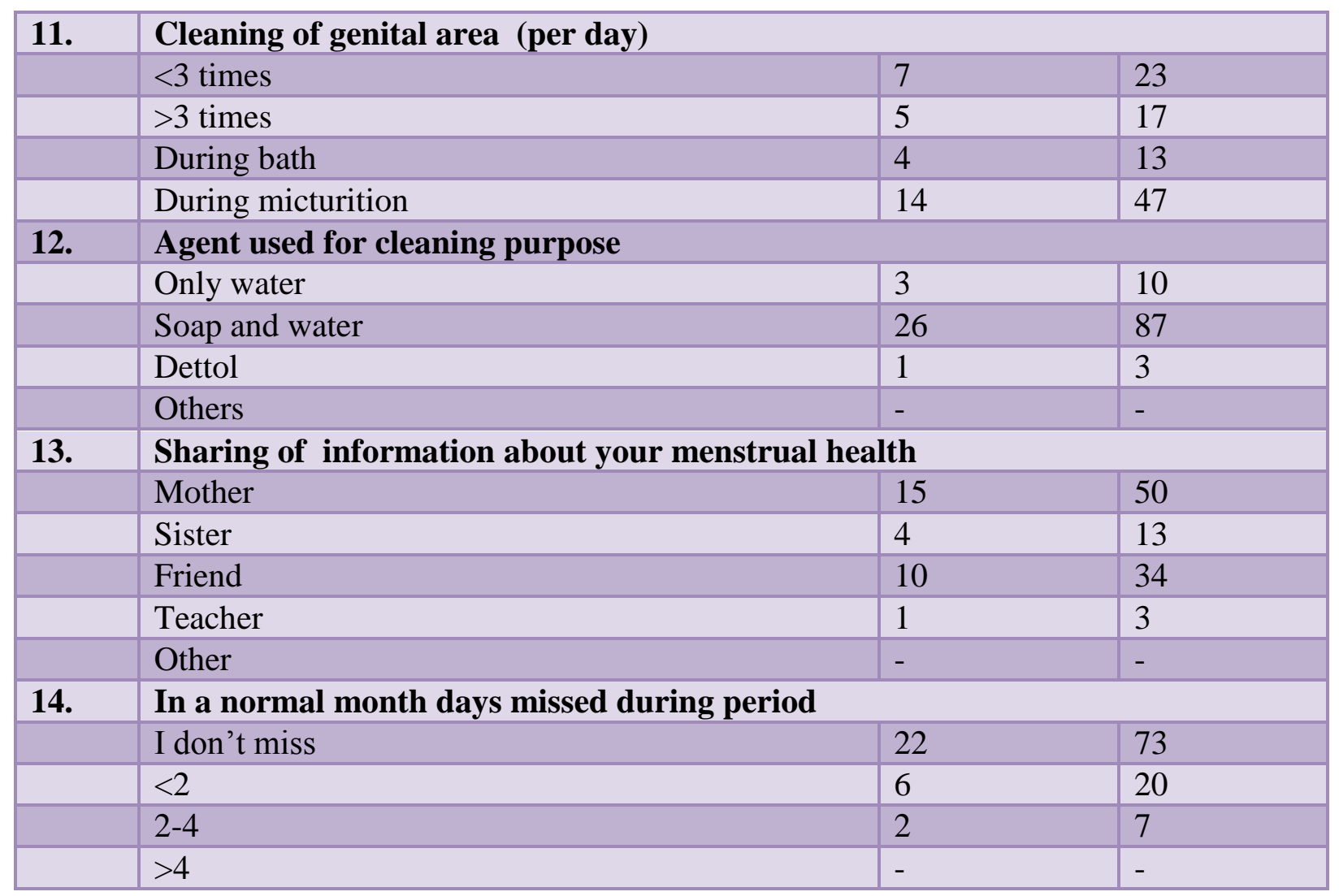

Existing knowledge about menstruation among adolescent girls

About $50 \%$ of the respondents do not have Knowledge about the organ from where bleeding occurs. Majority $73 \%$ of the respondents received information about menarche from their mothers (Table 2).

\section{Menstrual health practices among adolescent girls}

About $43 \%$ of the adolescent girls received menarche by the age of 12 years. Majority $83 \%$ of the adolescent girls have regular menstrual cycle. About $74 \%$ of the girls have normal flow of menstruation which shows that the respondents are healthy (Table 3).

Majority $77 \%$ of the adolescent girls change their absorbent material just less than 2 times a day. About $30 \%$ of the girls use cloth as menstrual absorbent material which shows poor practices in menstrual health.

Majority $60 \%$ of the respondents burn/bury the used menstrual absorbent which shows that the rural areas still believe in superstitions.

In conclusion, the main problem areas identified in this study were poor knowledge of menstruation, and hygiene practice in few areas. This study has highlighted the need of adolescent girls to have accurate and adequate knowledge about menstruation and its appropriate hygiene management. Formal as well as informal channels of communication such as mothers, sisters and friends need to be emphasized for the delivery of such knowledge.

Schools should be another entry point for improving menstrual health by integrating 
menstrual hygiene into curriculum. Menstrual health is an important part of life cycle approach to women's health, so loud and clear messages and services on this issue must reach adolescent girls.

Education has been the key stone in propagating menstrual hygiene practices. Although there is repeated sensitization and reinforcement of all these components among adolescent school girls, certain components are not being practiced. Strategies such as access to water, sanitation, hygiene of external genitalia and access to covered toilets are still deficient and it plays a major role to adopt safe practices.

\section{References}

Eijk, A.M.V., Sivakami, M., Thakkar, M.B., Bauman, A., Laserson, K.F., Coates, S. and Howard, P.A.P. 2016. Menstrual hygiene management among adolescent girls in India: a systematic review and meta-analysis. BMJ Open.

Hema, P.S., Nandi, P., Seetharaman N., Ramya M. R., Nishanthini $\mathrm{N}$ and Lokeshmaran A. 2017. A study of menstrual hygiene and related personal hygiene practices among adolescent girls in rural Puducherry. International Journal of Community Medicine and Public Health. 4(7): 2348-2355. http://vikaspedia.in/health/womenhealth/adolescent-health-1/menstrualhygiene-management

https://sswm.info/humanitarian-crises/ruralsettings/hygiene-promotion-communitymobilisation/hygiene-

promotion/menstrual-hygienemanagement

https://www.google.co.in/search?q=issue+of+ menstruation+in+present+era\&oq=issue +of+menstruation+in+present+era\&aqs $=$ chrome..69i57.16084j0j7\&sourceid $=\mathrm{c}$ hrome \&ie $=$ UTF- 8

https://www.indiafellow.org/blog/2017/07/me nstruation-practices-beliefs-mythstaboos/

Kendre, V.V and Ghattergi, C, H. 2013. A study on menstruation and personal hygiene among adolescent girls of government medical college, Solapur. National Journal of Community Medicine. 4(2): 272-276.

Questionnaire to assess Girls' Menstrual Hygiene Practices in East Africa. Questionnaire, version 11; 31st May, 2013.

Shoor, P. (2017). A study of knowledge, attitude, and practices of menstrual health among adolescent school girls in urban field practice area of medical college, Tumkur. http://www. ijournalhs.org/text.asp?2017/10/3/249/2 13999.

\section{How to cite this article:}

Deepa Amgoth and Geetha Reddy, R. 2019. A Study on Menstruation and Personal Hygiene among Adolescent Girls. Int.J.Curr.Microbiol.App.Sci. 8(02): 29-34. doi: https://doi.org/10.20546/ijcmas.2019.802.006 